\title{
PERFORMANCE DEMONSTRATION PROGRAM MANAGEMENT PLAN
}

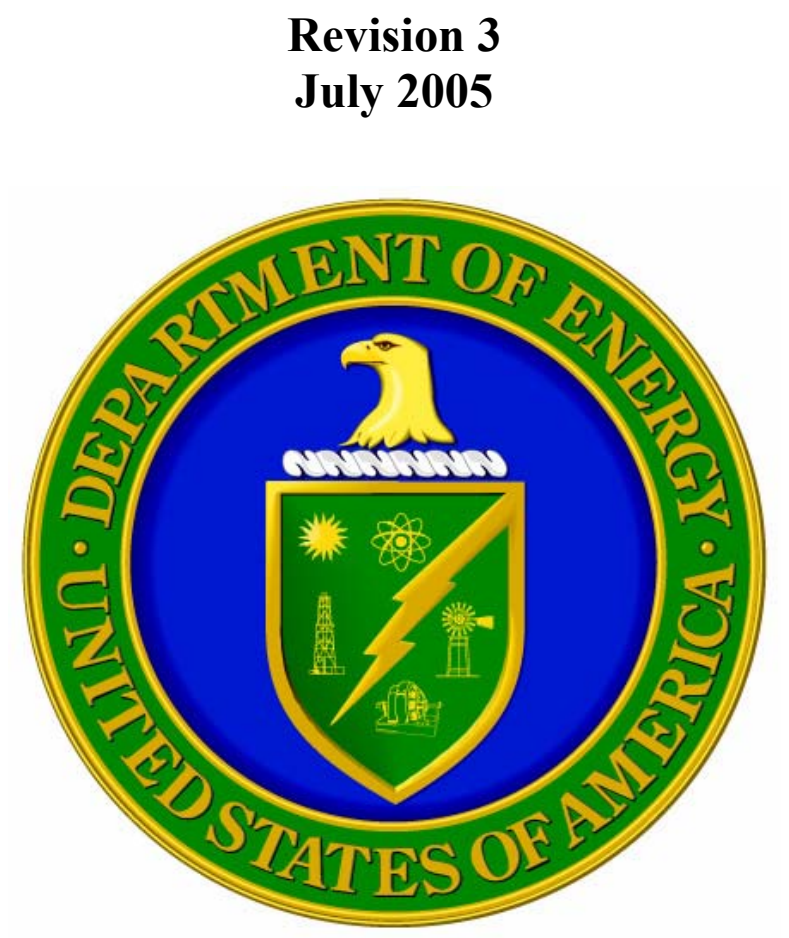

U.S. Department of Energy

Carlsbad Field Office

Office of Characterization and Transportation

This document supersedes revision 2 of

DOE/CBFO-01-3107 


\section{Performance Demonstration Program Management Plan}

DOE/CBFO-01-3107

Revision 3

July 2005

$\begin{array}{lll}\text { Approved By: } & \text { Approval on File } & \text { Date: } \\ & \text { Office Director } \\ \text { Office of Characterization and Transportation }\end{array}$

Concurred By: Approval on File

Date: Quality Assurance Manager

Prepared By: $\quad$ Approval on File

Date: PDP Appointee

Office of Characterization and Transportation 


\section{TABLE OF CONTENTS}

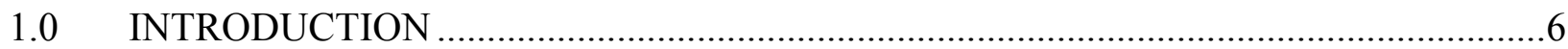

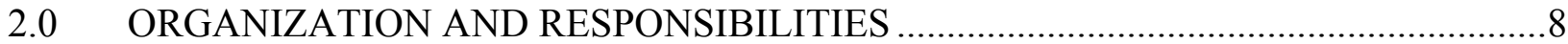

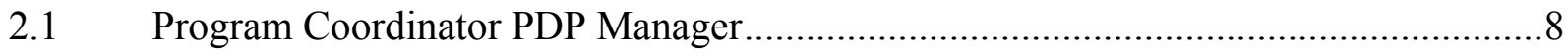

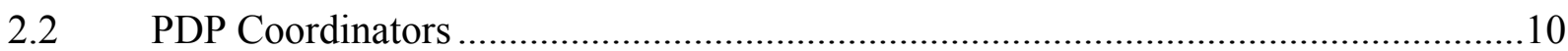

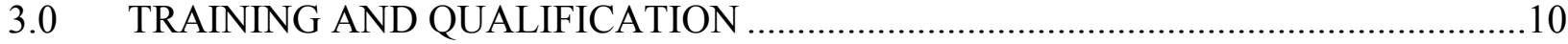

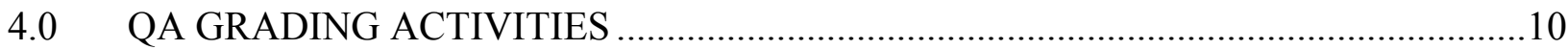

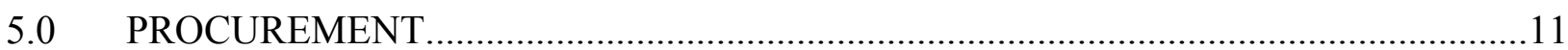

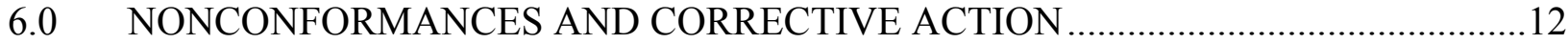

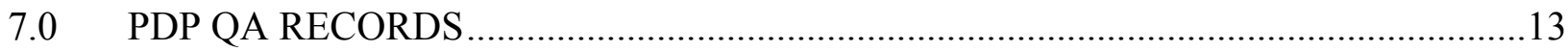

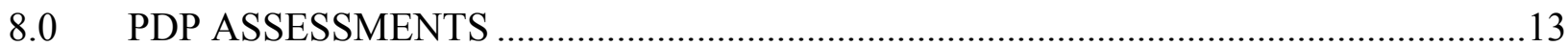

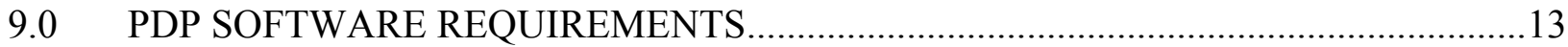

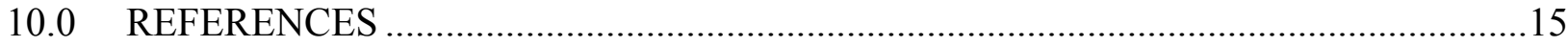

Attachment 1 CTAC Training Requirements for Performance Demonstration Program (PDP) Program Management Support to CBFO ……………............................................................16

\section{LIST OF FIGURES}

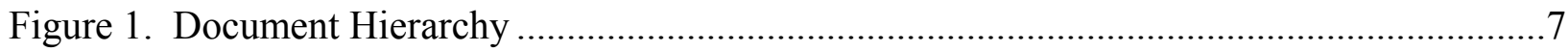

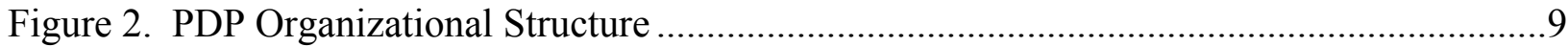




\section{ACRONYMS}

$\begin{array}{ll}\text { ANL-E } & \text { Argonne National Laboratory - East } \\ \text { CAR } & \text { Corrective Action Report } \\ \text { CBFO } & \text { Carlsbad Field Office } \\ \text { CCA } & \text { Compliance Certification Application } \\ \text { CRA } & \text { Compliance Recertification Application } \\ \text { DOE } & \text { Department of Energy } \\ \text { HSG } & \text { headspace gas } \\ \text { MP } & \text { Management Plan } \\ \text { NDA } & \text { nondestructive assay } \\ \text { NMED } & \text { New Mexico Environment Department } \\ \text { PDP } & \text { Performance Demonstration Program } \\ \text { QA } & \text { quality assurance } \\ \text { QAPD } & \text { Quality Assurance Program Document } \\ \text { RCRA } & \text { Resource Conservation and Recovery Act } \\ \text { TRU } & \text { transuranic } \\ \text { WAC } & \text { Waste Acceptance Criteria } \\ \text { WAP } & \text { Waste Analysis Plan } \\ \text { WIPP } & \text { Waste Isolation Pilot Plant }\end{array}$




\section{Significant Changes to the Performance Demonstration Program Management Plan, Revision 3}

\section{$\underline{\text { General }}$}

1. The Performance Demonstration Program (PDP) Management Plan was revised to enhance language associated with software verification and validation, supplier selection, and evaluation of supplier performance to ensure Carlsbad Field Office Quality Assurance Program Document (QAPD) requirements are met by PDP activities.

2. Editorial changes were incorporated as appropriate to improve technical clarity.

$\underline{\text { Specific }}$ (Section numbers refer to revision 2 unless otherwise noted)

Page 12-13 Basis for selection and evaluation of suppliers was revised to ensure conformance with the QAPD.

Page 14-15 Methods for verification and validation of calculations contained in Excel spreadsheets was added to ensure conformance to QAPD requirements. 


\subsection{INTRODUCTION}

To demonstrate compliance with the Waste Isolation Pilot Plant (WIPP) waste characterization program, each testing and analytical facility performing waste characterization activities participates in the Performance Demonstration Program (PDP). The PDP serves as a quality control check against expected results and provides information about the quality of data generated in the characterization of waste destined for WIPP. Single blind audit samples are prepared and distributed by an independent organization to each of the facilities participating in the PDP. There are three elements within the PDP: analysis of simulated headspace gases, analysis of solids for Resource Conservation and Recovery Act (RCRA) constituents, and analysis for transuranic (TRU) radionuclides using nondestructive assay (NDA) techniques. Because the analysis for TRU radionuclides using NDA techniques involves both the counting of drums and standard waste boxes, four PDP plans are required to describe the activities of the three PDP elements. Within the Carlsbad Field Office (CBFO), the Office of Characterization and Transportation oversees the elements of the PDP as described in the current revisions of the following plans:

- DOE/CBFO-01-1005, Performance Demonstration Program Plan for Nondestructive Assay of Drummed Wastes for the TRU Waste Characterization Program (Drum NDA PDP Plan)

- $\quad$ DOE/CAO-95-1076, Performance Demonstration Program Plan for Analysis of Simulated Headspace Gases (HSG PDP Plan)

- $\quad$ DOE/CBFO-95-1077, Performance Demonstration Program Plan for RCRA Constituent Analysis of Solidified Wastes (RCRA PDP Plan)

- $\quad$ DOE/CBFO-01-1006, Performance Demonstration Program Plan for Nondestructive Assay of Boxed Wastes for the TRU Waste Characterization Program (Box NDA PDP Plan)

In accordance with these PDP plans, the reviewing and approving authority for PDP results and for the overall program is the CBFO PDP Appointee. The CBFO PDP Appointee is responsible for ensuring the implementation of each of these plans by concurring with the designation of the Program Coordinator and by providing technical oversight and coordination for the program. The Program Coordinator will designate the PDP Manager, who will coordinate the three elements of the PDP.

The purpose of this management plan is to identify how the requirements applicable to the PDP are implemented during the management and coordination of PDP activities. The other participants in the program (organizations that perform site implementation and activities under CBFO contracts or interoffice work orders) are not covered under this management plan. Those activities are governed by the organization's quality assurance (QA) program and procedures or as otherwise directed by CBFO.

The primary documents governing the conduct of the PDP elements are CBFO-94-1012, Quality Assurance Program Document (QAPD); the WIPP Hazardous Waste Facility Final Permit (NM4890139088, as modified) and its associated Waste Analysis Plan (WAP); DOE/CBFO-19962184, Compliance Certification Application (CCA); DOE/WIPP 04-3231, the Compliance Recertification Application (CRA); and DOE/WIPP-02-3122, Waste Acceptance Criteria for the Waste Isolation Pilot Plant (WAC). These documents require each of the analytical laboratories and NDA 
systems that provide data for the characterization of TRU waste for disposal at WIPP to participate in the applicable PDP element. The four PDP plans implement the applicable general requirements of the QAPD. The RCRA and HSG PDP Plans implement applicable technical and quality requirements of the WAP, and the two NDA PDP Plans implement the requirements of the CCA, CRA, and the WAC. The management and coordination of the PDP are conducted in full compliance with applicable requirements. The relationship of the applicable documents is illustrated in figure 1. As shown in the figure, the PDP Plans are higher-level documents than the PDP Management Plan. Therefore, in cases where requirements specified in these plans conflict, the element-specific PDP Plan takes precedence.

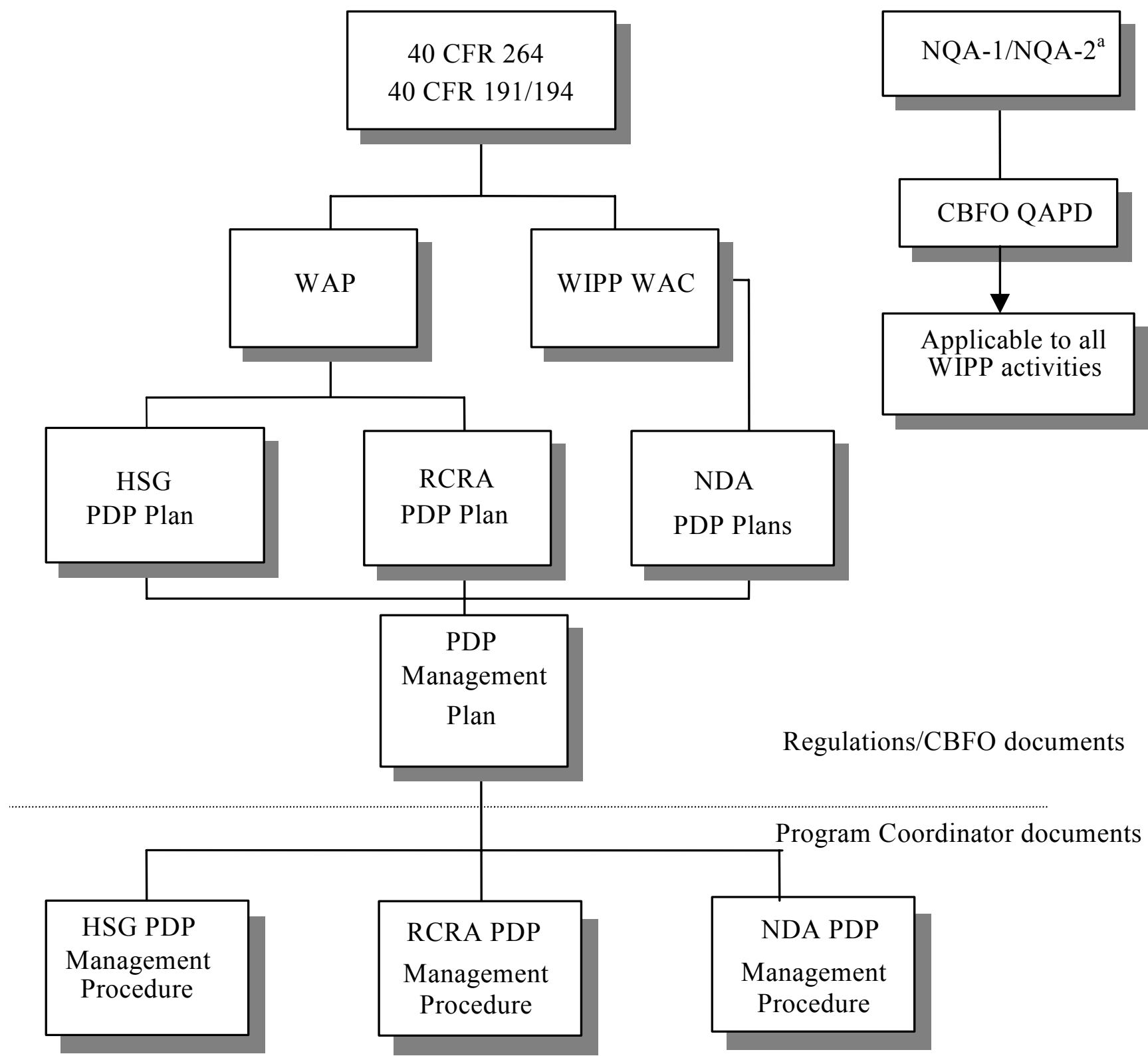

${ }^{\mathrm{a}}$ The complete reference for the applicable documents is: ASME NQA-1-1989 edition, ASME NQA-2a-1990 addenda, part 2.7 to ASME NQA-2-1989 edition, and ASME NQA-3-1989 edition (excluding Section 2.1 (b) and (c) and Section 17.1).

Figure 1. Document Hierarchy 
The Program Coordinator's PDP Manager shall ensure that procedures are prepared that serve as work instructions for each PDP element and implement the requirements of the applicable PDP plan(s) and this management plan. These procedures shall be reviewed by the CBFO Office of Characterization and Transportation PDP Appointee to ensure adequate implementation of the respective PDP plans.

This management plan will be promptly reviewed and revised as necessary to incorporate any changes in $\mathrm{CBFO}$ documents that affect the program, including the QAPD, WAP, WAC, CBFO management procedures (MPs), or PDP plan(s). The review of and any resultant changes to this management plan will be documented.

\subsection{ORGANIZATION AND RESPONSIBILITIES}

The CBFO oversees waste characterization being performed at the TRU waste sites and ensures that waste characterization requirements are met. The CBFO will assign an individual to perform as the PDP appointee. The CBFO PDP appointee is responsible as the reviewing and approving authority for all PDP activities and for providing technical oversight and coordination of the PDP. The CBFO PDP Appointee ensures implementation of the PDP by concurring with designation of the Program Coordinator. The Program Coordinator will designate the PDP Manager. The Program Coordinator administers PDP functions to qualify testing and analytical facilities that are active in waste characterization for the participating TRU waste sites. The CBFO, supported by the Program Coordinator, evaluates and approves individual facility performance for participation in the WIPP TRU waste disposal characterization program.

The organizational structure for implementing the PDP requirements is shown in figure 2 , and the responsibilities for implementing and managing the program within the contractor organization are discussed below.

\subsection{Program Coordinator PDP Manager}

The Program Coordinator assigns overall PDP responsibilities to the PDP Manager, who ensures that all PDP responsibilities identified in the PDP plans, and those implemented through this program management plan and the applicable CBFO MPs, are met. The PDP Manager:

- $\quad$ Routinely evaluates PDP performance in support of the CBFO and reviews and approves outgoing documentation associated with the PDP.

- $\quad$ Reports to the Office of Characterization and Transportation PDP Appointee and oversees and coordinates activities within the three PDP areas.

- $\quad$ Serves as the central point-of-contact for technical issues, scheduling, assessment interfaces, quality improvement, and other matters affecting the PDP.

- Designates a PDP Coordinator for each of the PDP elements.

- $\quad$ Provides prime direction to PDP Coordinator personnel for each of the PDP elements, prepares corrective documentation, and coordinates the preparation of PDP budget documents to ensure that adequate resources are available to meet program goals and milestones. 


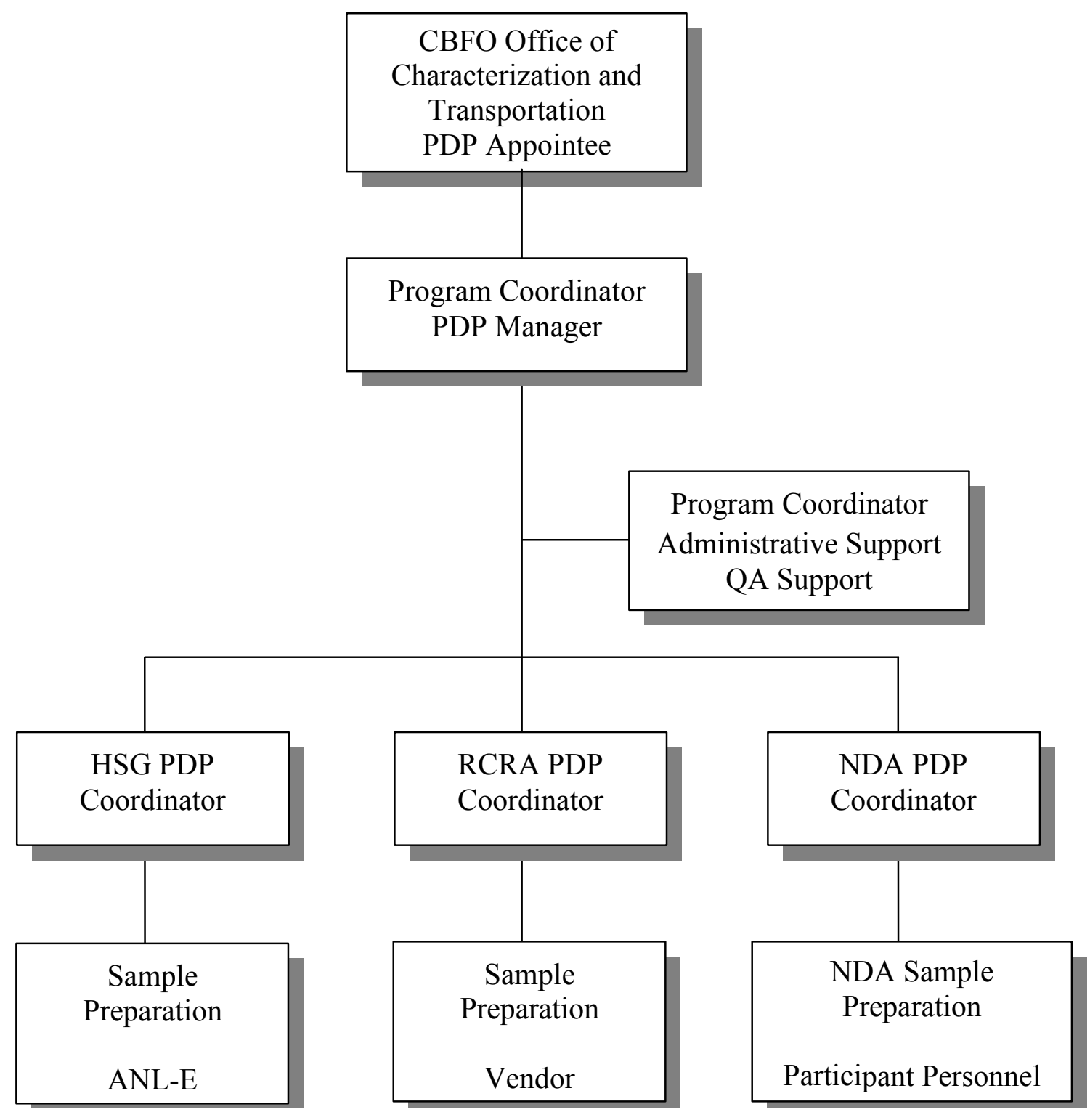

Figure 2. PDP Organizational Structure 


\subsection{PDP Coordinators}

Each PDP Coordinator is responsible for accomplishing the day-to-day tasks associated with the implementation of the PDP management plan. Tasks are defined in each of the PDP plans and are conducted in accordance with a PDP element-specific procedure or work instruction prepared by each PDP Coordinator and approved by the PDP Manager. PDP Coordinators are responsible for ensuring quality and for promptly reporting all potential conditions adverse to quality to the PDP Manager for evaluation and action in accordance with CBFO MP 3.1, Corrective Action Reports.

\subsection{TRAINING AND QUALIFICATION}

Personnel involved in PDP management activities shall be qualified and trained as follows.

At a minimum, the PDP Manager and PDP Coordinator personnel shall have at least a bachelor's degree in science or engineering and at least five years of professional experience related to the type of PDP activities that are being coordinated. Qualification and contractor training documentation shall be entered into the CBFO records system. The PDP Manager is responsible for selecting qualified personnel and ensuring that they complete the appropriate training.

Training requirements for PDP personnel include reading the current revision of the following documents, as applicable. The reading shall be documented on the form provided in attachment 1 or on an equivalent form.

- CBFO QAPD

- WAP

- WAC

- PDP Plan(s) (HSG, RCRA, and NDA)

- CBFO MP 1.2, Selection of Quality Levels

- CBFO MP 3.1, Corrective Action Reports

- CBFO MP 4.5, Generating, Receiving, Storing, and Controlling Active CBFO Project Records

- Contractor MPs for each of the PDP elements

- PDP Management Plan

- Other documents as identified by the PDP Manager

The discipline-specific training required for each PDP Coordinator shall be identified in the applicable management procedure(s). Documentation of completed training is maintained in QA records in accordance with CBFO MP 4.5, Generating, Receiving, Storing, and Controlling Active CBFO Project Records.

\subsection{QA GRADING ACTIVITIES}

The CBFO, assisted by the Program Coordinator, will perform PDP activity grading in accordance with CBFO MP 1.2, Selection of Quality Levels, and will also document and retain the evaluation as required by MP 1.2. The grading applies only to the specific controls placed on the activity and not the requirements. In no case will requirements be graded out of the program. 


\subsection{PROCUREMENT}

The Program Coordinator, as the entity responsible for PDP activities, implements procurements for continuing operations of the PDP. These may include procurements for:

- $\quad$ Consultant support contracts to obtain the services of an individual with extensive experience in developing and maintaining operations of the PDP

- Supplier procurement contracts with commercial laboratories for sample preparation and verification support efforts or with commercial suppliers for manufacture of PDP equipment and accessories (e.g., NDA PDP drums, boxes and the spare parts associated with these items)

Procurements may involve subcontractors who have previous, documented, and acceptable performance in support of the PDP. No procurement will exceed the scope of work currently being performed. All applicable procurement requirements of the QAPD shall be met. PDP procurements conducted by the Program Coordinator will be in accordance with procedures written to support the procurement function and will be performed as follows.

Typically, procurement documentation is prepared by the applicable PDP Coordinator and reviewed and approved by the PDP Manager. The PDP Manager, Program Coordinator's Contracts Administrator, and a QA support individual shall ensure that all applicable elements required by the QAPD are appropriately incorporated in the procurement documents. The PDP Manager is responsible for final review and approval of procurement documentation and for ensuring that the applicable QAPD procurement requirements and the contractor organization's procurement requirements are addressed. All parties shall document their review and approval by signing the approval pages of the procurement documentation.

The Program Coordinator's Contracts Administrator, in conjunction with the applicable PDP Coordinator, shall select the procurement source and document the basis for selection.

Suppliers will be selected consistent with the requirements for supplier selection specified in the QAPD. Prospective suppliers shall initially be evaluated and selected on the basis of documented criteria and the PDP Manager shall verify that approved suppliers continue to provide acceptable items and services. Supplier selection shall be based on evaluation of the supplier's capability to provide items or services in accordance with procurement document requirements by performing one or more of the following elements:

1. An evaluation of the supplier's history for providing an identical or similar product that performs satisfactorily in actual use.

2. An evaluation of the supplier's current QA documentation, supported by any documented qualitative and quantitative information.

3. An evaluation of the supplier's technical and QA capability, based on an evaluation of the supplier's facilities, personnel, and quality program implementation.

When a supplier has previously and successfully supported the PDP Program, a surveillance or an evaluation of the supplier's continued performance shall be performed at least every three years. 
Evaluations are performed of the supplier's history for providing an identical or similar product that performs satisfactorily in actual use and of the current QA documentation, supported by any documented qualitative and quantitative information in accordance with approved implementing procedures to determine continued satisfactory performance. These surveillances or evaluations shall be performed more frequently if performance problems are encountered or other situations develop that suggest a surveillance or an evaluation is needed.

Supplier bids shall be evaluated based upon the following criteria:

- $\quad$ Conformance to the procurement documents (statement of work)

- Technical considerations

- QA requirements

- $\quad$ Prospective supplier's personnel, production capability, past performance, and any exceptions taken. All unacceptable quality conditions shall be resolved prior to order placement.

The applicable PDP Coordinator will perform and document an annual review of each subcontracted supplier or conduct receipt inspections to ensure the supplier is performing acceptably. Documentation of this review may be in the form of a formal report or a renewed contract for services in the upcoming year. If the results of the review indicate the need, an onsite assessment will be performed.

The responsible PDP Coordinator shall review and document acceptance of the supplier's deliverables to ensure that they meet the procurement requirements. The PDP Coordinator shall also review and approve the disposition of any PDP supplier nonconformance documentation.

Changes to procurement documents require the same degree of control and review as the original procurement documents. Procurement documents and other records generated during the procurement of PDP items and services are QA records. QA records shall be processed in accordance with CBFO MP 4.5, Generating, Receiving, Storing, and Controlling Active CBFO Project Records. PDP procurement QA records have been determined to be nonpermanent.

Some suppliers to the PDP may be entities that are not procured by the Program Coordinator. Rather, they are DOE facilities that obtain funding directly from CBFO. For these suppliers, the CBFO PDP Appointee shall designate the frequency of audits, assessments, and/or surveillances consistent with QAPD requirements or more frequently.

\subsection{NONCONFORMANCES AND CORRECTIVE ACTION}

A corrective action report (CAR) will be written in accordance with CBFO MP 3.1, Corrective Action Reports, whenever a condition adverse to quality is identified. PDP support supplier performance is measured as an inherent part of each RCRA and HSG PDP cycle. In the RCRA PDP, the supplier conducts confirmatory analyses that verify analyte concentrations believed to be in the PDP samples. Somewhat similarly, in the HSG PDP a CBFO support organization conducts confirmatory analyses of gas mixes prepared and certified by a commercial supplier. When the majority of participant results agree with the known analyte concentrations, the supplier performance is further confirmed. However, if all TRU waste sites report a different result, with a similar bias, it may indicate a supplier problem with the sample preparation and/or verification analysis. In such cases, in accordance with the RCRA 
and HSG PDP Plans, the result for any such analyte(s) may be discarded, and a CAR will be initiated. When a CAR is initiated, appropriate remedial actions, investigation, root cause determination, and actions to preclude recurrence will be implemented in accordance with CBFO MP 3.1.

\subsection{PDP QA RECORDS}

PDP QA records are designated as nonpermanent. All PDP documents classified as QA records that are prepared by the contractor in its PDP support capacity shall be transmitted to the CBFO for appropriate management and retention. Documentation in process is maintained with reasonable protection prior to completion. (In accordance with the CBFO QAPD, documentation is not considered to be a QA record until it has been completed.) CBFO accepts the data, approves the final issuance of results and other documentation, and processes the records in accordance with CBFO MP 4.5, Records Management.

Records generated by participants that are associated with PDP analyses and measurements are considered QA records and must be maintained by the individual participant in accordance with the CBFO QAPD (section 1.5, Records).

PDP QA records are identified in each PDP plan. For each of the PDP elements, the corresponding procedure or work instruction should include the specific records that are generated during PDP implementation. QA records management, including disposition, when applicable, will be maintained in accordance with CBFO MP 4.5, Records Management.

\subsection{PDP ASSESSMENTS}

Other than the routine reviews of internal activities, no other QA assessments are performed by the Program Coordinator PDP Manager relative to the PDP. CBFO performs assessments of the PDP on a periodic basis, not to exceed three years. These assessments are performed in accordance with the requirements of the CBFO QAPD.

\subsection{PDP SOFTWARE REQUIREMENTS}

Any PDP software used for scoring analytical and other measurement results (i.e., spreadsheets developed using commercial software such as Excel) shall be in conformance with QAPD requirements. Commercial software is exempt from the software control requirements of section 6.0. However, the applications of such commercial software are not exempt from the software control requirements of section 6.0 .

Spreadsheet applications produced using the software shall be fully documented and validated according to applicable QAPD requirements. The PDP Coordinators are responsible for ensuring that any spreadsheet development and use is properly documented and validated.

Any spreadsheet developed and used for a PDP activity to obtain final results shall be identified with a revision or version number. Since these spreadsheets will be used only by the coordinators and possibly a trained backup individual, software distribution and control does not pose a concern. Any newly developed spreadsheets used to obtain final results and any changes to existing spreadsheets used to obtain final results shall be validated by comparing software results with hand calculations or other appropriate means. Any subsequent revision shall be revalidated by comparing the new results with the values obtained before the change or through some other comparison. The specific validation 
tests shall be designed to cover the entire range of interest and shall be documented. Records associated with validation of such scoring spreadsheets shall be maintained in the CBFO records system.

If an Excel spreadsheet is used to obtain final results, the calculations performed by the spreadsheet will be verified and validated by verifying that the spreadsheet works correctly over the expected range of the input variables, and documented by issuing a memo record containing the following information to the CBFO PDP Appointee:

- Name and version of the software used

- Name and version number (required) of the spreadsheet, and the name of the developer

- Scope of the computation

- Data entry process description

- List and definition of named variables

- Definition of complex formulas (i.e., formulas not easily deduced by inspection of the spreadsheet or macro)

- Documentation of the verification of the software (by hand calculation or other means)

- An electronic disk copy of the spreadsheet set up to run one of the documented verification tests

- Inputs, output results, and ancillary data (if used)

If spreadsheets containing formulas are used to obtain preliminary results, the results of all formulas used in the spreadsheet must be verified and documented prior to using the results as final data. 


\subsection{REFERENCES}

DOE/CBFO-94-1012, Quality Assurance Program Document, current revision, U.S. Department of Energy Carlsbad Field Office.

DOE/CBFO-1996-2184, Title 40 Part 191, Compliance Certification Application for the Waste Isolation Pilot Plant, U.S. Department of Energy Carlsbad Field Office.

CBFO MP 4.5, Generating, Receiving, Storing, and Controlling Active CBFO Project Records, current revision, U.S. Department of Energy Carlsbad Field Office.

CBFO TP 10.1, Qualification of Audit Personnel and Certification of Lead Auditors, current revision, U.S. Department of Energy Carlsbad Field Office.

CBFO MP 3.1, Corrective Action Reports, current revision, U.S. Department of Energy Carlsbad Field Office.

CBFO MP 1.2, Selection of Quality Levels, current revision, U.S. Department of Energy Carlsbad Field Office.

CBFO MP 10.2, Surveillances, current revision, U.S. Department of Energy Carlsbad Field Office.

CBFO MP 10.3, Audits, current revision, U.S. Department of Energy Carlsbad Field Office.

DOE/WIPP-02-3122, Contact-Handled Transuranic Waste Acceptance Criteria for the Waste Isolation Pilot Plant, current revision, U.S. Department of Energy Carlsbad Field Office.

DOE/CBFO-01-1005, Performance Demonstration Program Plan for Nondestructive Assay of Drummed Wastes for the TRU Waste Characterization Program, current revision, U.S. Department of Energy Carlsbad Field Office.

DOE/CAO-95-1076, Performance Demonstration Program Plan for Analysis of Simulated Headspace Gases, current revision, U.S. Department of Energy Carlsbad Field Office.

DOE/CBFO-95-1077, Performance Demonstration Program Plan for RCRA Constituent Analysis of Solidified Wastes, current revision, U.S. Department of Energy Carlsbad Field Office.

DOE/CBFO-01-1006, Performance Demonstration Program Plan for Nondestructive Assay of Boxed Wastes for the TRU Waste Characterization Program, current revision, U.S. Department of Energy Carlsbad Field Office.

DOE/WIPP 04-3231, 40 CFR Part 191 and 194, Compliance Recertification Application for the Waste Isolation Pilot Plant. U.S. Department of Energy Carlsbad, New Mexico.

NM4890139088, Hazardous Waste Facility Final Permit, as modified, New Mexico Environment Department, Santa Fe, New Mexico. 


\section{Attachment 1 \\ CTAC Training Requirements for Performance Demonstration Program (PDP) Program Management Support to CBFO}

NAME:

POSITION:

1. Prior to performing quality-affecting work, training must be completed and documented on this form.

2. Specific training requirements for your position are identified by an " $X$ " in the "Req." column.

3. Be sure to document the training for the last revision of the document; list the revision number.

4. List the Training Type(s) used:

$\mathrm{C}=$ Classroom

$\mathrm{R}=$ Reading

$\mathrm{B}=$ Briefing

$\mathrm{T}=$ Test Required at Completion

5. As each training element is completed, sign and date in the columns provided for that element.

\begin{tabular}{|l|l|l|l|l|l|}
\hline \multicolumn{1}{|c|}{ Training Element } & Req. & Rev. & $\begin{array}{l}\text { Training } \\
\text { Type(s) }\end{array}$ & Signature & Date \\
\hline CBFO QAPD (CBFO-94-1012) & & & & & \\
\hline $\begin{array}{l}\text { WIPP RCRA HWFP WAP, including } \\
\text { Attachments 1 and 3 }\end{array}$ & & & & & \\
\hline WIPP WAC & & & & & \\
\hline CBFO HSG PDP Plan (DOE/CAO-95-1076) & & & & & \\
\hline CBFO RCRA PDP Plan (DOE/CBFO-95-1077) & & & & & \\
\hline CBFO Drum NDA PDP Plan (DOE/CBFO-01-1005) & & & & & \\
\hline CBFO Box NDA PDP Plan (DOE/CBFO-01-1006) & & & & & \\
\hline $\begin{array}{l}\text { CBFO PDP Management Plan } \\
\text { (DOE/CBFO-01-3107) }\end{array}$ & & & & & \\
\hline $\begin{array}{l}\text { CTAC MP 2.5, "Conduct of Headspace Gas } \\
\text { Performance Demonstration Program" }\end{array}$ & & & & & \\
\hline $\begin{array}{l}\text { CTAC MP 2.6, "Conduct of the RCRA Performance } \\
\text { Demonstration Program" }\end{array}$ & & & & & \\
\hline $\begin{array}{l}\text { CTAC MP 2.7, "Conduct of the Non-Destructive } \\
\text { Assay Performance Demonstration Program" }\end{array}$ & & & & & \\
\hline CBFO MP 1.2 ICN\#1, "Selection of Quality Levels" & & & & & \\
\hline CBFO MP 3.1, "Corrective Action Reports" & & & & & \\
\hline $\begin{array}{l}\text { CBFO MP 4.5, "Generating, Receiving, Storing, and } \\
\text { Controlling Active CBFO Project Records" }\end{array}$ & & & & & \\
\hline WIPP General Employee Training & & & & & \\
\hline Other & & & & & \\
\hline Other: & & & & & \\
\hline
\end{tabular}

Training Assigned By:

Date:

Training Completion Verified By:

Date: 